\title{
HAPPY AGEING WITH OR WITHOUT TECHNOLOGY? A CASE STUDY
}

\author{
Carla Chiellino and Thomas Keller \\ ZHAW School of Management and Law, Winterthur, Switzerland
}

\begin{abstract}
This paper presents an interactive narrative with scenarios about the future development of elderly care. The main goal of this narrative is the triggering of a discourse about possible future situations and which of these situations are desirable from a subjective point of view and which ones should avoided. The elaboration of the interactive narrative is based on a PESTLE analysis and uses the science-fiction prototyping method. The first of three stages play in the present whereas the other two stages are at two different points of time in the future. This interactive narrative which is online available in German and English was used for six probands which went through the whole story. To capture their opinions and perceptions the think aloud method was applied. It seems that such interactive narratives can indeed trigger a discourse and be a starting point for a constructive discussion.
\end{abstract}

\section{KEYWORDS}

Interactive Narrative, Happy Ageing, Science-Fiction Prototyping, Responsible Innovation

\section{INTRODUCTION}

With population growth, climate change, increasingly scarce resources at all levels and technological changes in the work process, future generations are facing major challenges (Khairul et al., 2018). The idea of what our world might look like in the future has always fascinated and frightened people. It is not for nothing that science fiction films and books with their visions and outlooks into a fantastic future enjoy great popularity. Partially driven by demographic change, the elderly care of the future will also change. What the future will actually look like can only be assumed at this point in time. There is no question, however, that technological changes and opportunities will also be introduced in this segment, which has rather been traditional up to now.

The health care system and thus the care of the elderly are most clearly affected by demographic change. By 2050, the number of people in need of care in the western world will increase significantly. The shortage of skilled workers in the health care system, which is already being discussed today, will then become even more apparent. It is already foreseeable today that emerging technologies will also have to be used in the care sector to counteract this problem of undersupply (Es Wird Ernst Mit Dem Demografischen Wandel! | Avenir Suisse, n.d.).

Not only the lack of skilled workers is driving this development, but also the senior citizens' need for autonomy can promote the entry of emerging technologies. The idea that in many areas they can no longer determine their own lives and can only manage everyday activities with help is frightening for many senior citizens. Therefore, technologies are being sought that promise this autonomy for elderly people (Bleses, 2019, p. 4; Kubek, 2020; Zettl \& Trübswetter, 2018).

In addition to autonomy, people also strive for competence and solidarity. Since these three factors are interdependent, they all decrease with age (Behrens \& Zimmermann, 2006). This study was originally conducted by Edward L. Deci and Richard M. Ryan. The Self-Determination Theory is an empirically derived theory of human motivation and personality in social contexts, distinguishing between autonomy and control in terms of motivation (Ryan \& Deci, 2000). 


\section{RESEARCH OBJECTIVE}

The aim of this paper is to take a closer look at the challenges of future elderly care for highly developed countries using the example of Switzerland and thus to work out development scenarios. In doing so, conceivable applications of new technologies in concrete situations are presented as narratives and thus easier to imagine for a group of test persons. This procedure is intended to trigger a discourse about possible characteristics of our digital future and their acceptance. The aim is not only to find out which technologies could be used in the future, but above all to find out whether people consider them conceivable and desirable. This work also shows the extent to which narrative development scenarios are suitable for stimulating discourse.

\section{RESEARCH DESIGN}

In order to tackle the research objectives defined above, different methodological approaches were combined. A literature research served to obtain an overview of the entire domain. The environment for the development of the multilinear story was prepared by means of a PESTLE analysis (Salzburg Research, n.d.) and Science-Fiction prototyping (Johnson, 2011; Pirker et al., 2014). The Think Aloud method (Someren et al., 1994) helped to record the subjects' thought processes for later evaluation. Elements of the design-science approach (Hevner et al., 2004) are incorporated into the development and verification of the artifact.

The interactive story was divided into three chronological stages. Thus each of these stages contains a macro, meso and micro level. This allows the test person to experience the stages on different levels and to empathize with the situation. The first stage is based on a performed PESTLE analysis. The other stages were developed using science fiction prototyping. The key technologies, which were evaluated by means of literature research, are shown on the micro level. After writing the story, it was published as a Twine (Twine / An Open-Source Tool for Telling Interactive, Nonlinear Stories, n.d.).

\section{PSYCHOLOGICAL AND TECHNOLOGICAL BACKGROUND}

In the following sections, the Self-Determination Theory (Deci \& Ryan, 2010) is explained, as it seems to be highly relevant for the chosen domain of elderly care. Subsequently, the technologies relevant for the work are described in more detail.

\subsection{Self-Determination Theory}

The Self-Determination Theory (SDT) was developed by Ryan and Deci and is an empirically derived theory of human motivation and personality in social contexts. It distinguishes between autonomy and control in terms of motivation (Deci \& Ryan, 2010). This theory is based on the work of experts who studied the effects of extrinsic rewards on intrinsic motivation.

It is already known in social psychology that the forces of the environment can have a considerable influence on people's attitudes, values, motivation and behavior. Therefore, the focus of self-determination theory is on the influence of social environments on attitudes, values, motivation and behavior, both in development and in current situations (Deci \& Ryan, 2010). In theory, however, it is assumed that the human organism develops in such a way that it is inherently active, intrinsically motivated and designed to develop naturally through integrative processes.

Humans need biological, but also psychological nutrients so that these natural, active processes of intrinsic motivation and integration can have a positive effect on healthy development and psychological well-being. If these nutrients are missing, the natural processes connect with each other, which leads to experiences, developments and behaviors that are not optimal. In SDT, psychological nutrients and their dynamics within the social environment are mainly considered. According to SDT, based on decades of empirical work, there are at least three universal psychological needs: the needs for competence, autonomy and connectedness (Deci \& Ryan, 2010). The need for competence leads people to strive to control results and experience the effect. 
This includes understanding the tools that lead to the desired results and being able to use them reliably. Autonomy is understood as the aspiration of people to be active, to feel as the origin of their actions and to contribute to determining their own behavior. From the need for social connectedness results the striving of the person to build up a relationship with other people and to care for them.

These three psychological needs decrease with age. Since physical as well as mental strength diminishes with age, a person has to give up a part of his freedom and self-determination (Behrens \& Zimmermann, 2006). He also loses competence and no longer has the same opportunities to maintain social contacts. Since in psychology these three factors are regarded as basic human needs, this is a significant limitation for older people. In order to overcome such limitations, various technologies can be used, which will not be discussed conclusively in the following section.

\subsection{Emerging Technologies}

Emerging technologies are already being used to support the care of senior citizens. Sensor technology, robotics and smart gadgets not only make it possible to support the caregivers, but also help the person in need of care to maintain a certain degree of autonomy. There are retirement homes where the use of robots has been tested on residents. Acceptance was usually high, which is often due to the fact that such robots already exhibit certain human characteristics. Other technologies, which are rather abstract in nature and do not, or only remotely, resemble a human or an animal, are viewed rather sceptically by the older generation. However, it can be assumed that this will change over time. Future generations of senior citizens will have already grown up with such technologies and will therefore no longer have any fear of contact.

Autonomous robot and assistance systems. Robots, especially those of the next generation, are capable of perceiving their environment and reacting to stimuli and influences ( $\mathrm{Li}$ et al., 2017). They exist in different variants and can perform different tasks, ranging from small vacuum cleaner robots to large, driverless robots that can load containers and crates. A precise differentiation is not easy due to the multifunctionality (Demenz Und Technologie - Eine Trendübersicht (Gedruckt): Alzheimer Schweiz, n.d.).

Human-robot collaborations take place in many areas of industry. Research has shown that these collaborations can also be effective in the field of care. There are already prototypes of humanoid robots that can imitate nursing procedures and can take over this task completely in the future. In an area of robotics research, we are investigating how caregivers, with respect to whom there will be a shortage in the future, can be replaced. For example, there are also robots that have an entertainment purpose or can be used as a substitute for pets. An important field of application for robots in care is the support of errands. In addition, there are already robots that can easily pick up a person and put them in a wheelchair (Bendel, 2018). At present, robots tend to take over simple routine tasks, but this can also be a relieving aid. In the future, it may be possible that caregivers will be completely replaced by robots (Rieger, 2019).

The diversity of this key technology enables it to influence all three elements of the theory of -determination. By using assistance robots, autonomy can be maintained even in old age. More complex robotic systems can help to train the physical, but also mental abilities of a human being so that they are maintained as long as possible. The more humanoid robots with which conversations can be conducted, as well as pet robots, can give humans a sense of belonging.

Smart Home. A technological equipment (Marikyan et al., 2019) of the own living space can enable senior citizens to stay there as long as possible without any danger and thus to maintain their own autonomy. This key technology can also be used in various ways. The area that focuses on assistance functions for people in need of help is called Ambient Assisted Living (AAL) (Calvaresi et al., 2016). Classic smart home functions such as automated climate control, lighting and shading, control of electrical circuits and devices, and security functions are used here. In addition, AAL offers further assistance functions that are designed to enable independent living in familiar surroundings (Wisser, 2018). On the one hand, there are special sensors and actuators that are integrated into the house or apartment, and on the other hand, there are technologies for exchanging information and communication. In case of abnormalities, relatives or caregivers are informed so that they can be involved in certain situations and decision-making. In addition, the vital functions of the seniors can be recorded, stored in a database and forwarded if necessary. By means of sensors in the floor and a related position or impact detection, a fall of the person can also be detected. Many of the AAL technologies are based on live data, which are immediately processed and interpreted. There are already innovative variants that include a self-learning system. Thus, objects, persons and their activities can be recognized and at the same 
time the collected data can be interpreted (Wisser, 2018). AAL devices take a lot of work off the shoulders of users. On the one hand, this is supportive, but on the other hand it also takes away exactly the work that people have been able to do independently throughout their lives. Especially in retirement homes, it is observed that new senior citizens find it difficult and miss tasks such as washing, cooking or cleaning. Thus, these key technologies not only help to maintain the elements of SDT, they can also minimize them.

Invasive Technologies. Nanorobots (Li et al., 2017) as well as brain interfaces (Martini et al., 2020) belong to technologies that penetrate under the skin of humans. Nanorobots are tiny robots that reside and move inside the human body. A nanorobot is ten times larger than a hydrogen atom and thus 50,000 times smaller than the diameter of a human hair. In medicine, the use of nanorobots is aimed at repairing areas of the brain or using them for drug administration. A brain interface can be designed in different ways. One approach is based on electroencephalography (EEG) (Biasiucci et al., 2019), which measures electro-magnetic fluctuations in the brain through electrodes attached to the scalp. By concentrating or relaxing in a targeted manner, the human being can give simple instructions to the machine. Another approach works by means of direct connection to the brain by placing a chip under the skull, which penetrates the brain with fine electrodes.

\section{THE MULTILINEAR STORY}

The fundamental characteristic of a multilinear story (Brucker-Kley \& Keller, 2020a, 2020b, 2019) is that there are several lines of action along a causality chain. Originally, this multilinearity stems from the modelling of alternative actions in multilinear environments. An example of this are computer games. Another term for multilinear narratives is interactive narration. Users can decide on actions themselves and thus influence the progress of the story. This structure is often applied in the entertainment genre but is also used in more serious areas such as education and training. The most common form of an interactive narrative is characterized by the users taking on the role of the protagonist in an unfolding plot. In the story that is used in the framework of this work, the users also take on the role of the protagonist and can thus influence the course of the story (Behles, 2009; Koenitz et al., 2015; Pirker et al., 2014).

The story is written on three different levels. On the macro level, the environment in which the protagonist is currently living is considered. This includes political, economic, ecological, social, technological and legal factors. This environment cannot be influenced by the players. The meso-level, on the other hand, can be partially influenced by the players. This is the environment in which the person lives, e.g. their own apartment or a retirement home. Then there is the micro-level, which comprises the individual decisions of the protagonist. This concerns the technologies that this person wants to use or does not want to use and the treatments that should or should not be approved (Behles, 2009).

Within the three stages described below, future technologies and developments are discussed and speculated on. Figure 1 shows an overview of the decision points in the story. The interactive narrative is available online in the original German version (Brucker-Kley Elke, 2020) and in a partially machine translated English version.

The first stage takes place in 2020 and thus represents the present.

The second stage begins in 2035. Fifteen years after the beginning of the story, not only the person has changed, but also the environment in which they live and move. For this stage, the factors at the macro level are partly substantiated by futurology, but often assumptions had to be made. It is already clear in 2020 that IoT and AI will change lives. Even if many solutions still seem rudimentary and much is only available as a concept study, the potential has already been recognized. Renowned scientists are firmly convinced that the point in time when AI can exceed human intelligence will be reached within a few years. The future will show to what extent these predictions are true. However, it is undisputed that another technological revolution will take place between 2035 and 2050. Robots and devices with capabilities that are hardly imaginable today will then be commonplace. This will not only change society and daily life, but also the way senior citizens are cared for and looked after.

The third stage takes place again 15 years later, starting in 2050. In 2006, Ray Kurzweil (Kurzweil, 2005) claims that the point of technological singularity would be reached within a few decades. This means the point in time when AI will surpass human intelligence, thereby rapidly improving itself and developing new inventions. Whether this point in time will ever be reached, and if so, when this will be the case, is still a matter of controversy in 2020. For the course of the story told here, it is assumed that AI and robotics have developed 
in such a way that technologically there are no longer any limits for the care of the elderly. This does not mean, however, that all possibilities are being used. Factors such as costs, laws or moral concepts can create new barriers. During this phase, the test persons are presented with a number of options that are currently only known from science fiction movies and are unthinkable at this point in time. The idea behind this is to register the reactions triggered by these options.

The decision points offered by the interactive story for the three stages can best be experienced by going through the German or English online versions. Please use Figure 1 for an overview.

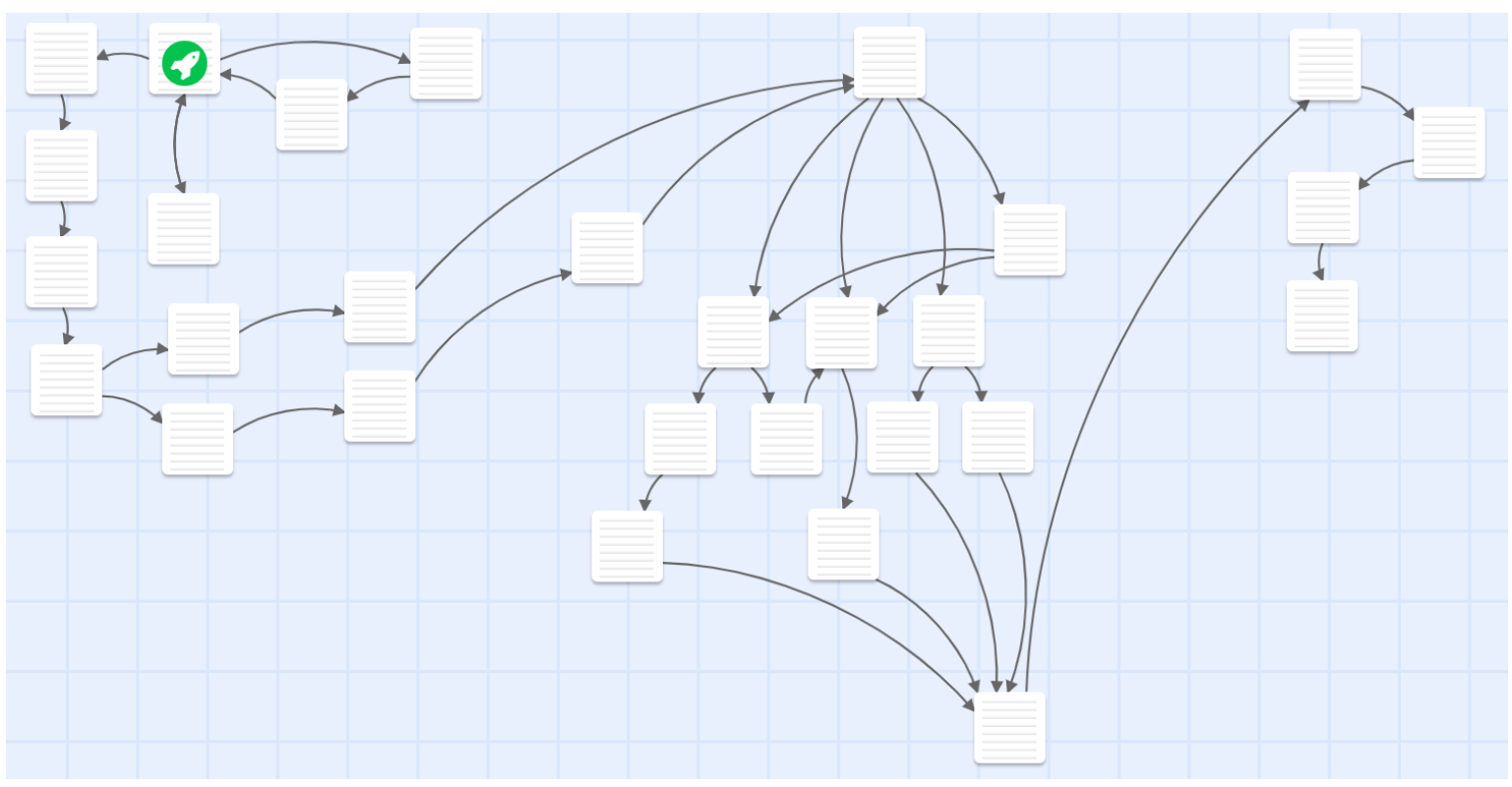

Figure 1. The structure of the multilinear narrative

\section{THE QUALITATIVE SURVEY}

Due to Covid-19 based restrictions only six probands of different age groups experienced the multilinear story. At the beginning of each survey, the following questions were asked on the topic to gain insight into the person's attitude:

1. Can you imagine living in a retirement home one day?

2. Would you seek external help (drugs, technology) to live as long as possible?

3. Are you afraid of the development of retirement provisions?

4. Would you rather entrust your life to a human or a machine?

5. What is your general attitude towards new technologies?

After the interview, the probands were introduced to the story, but were then asked to go through the interactive narrative independently. In addition, they were asked to express their thoughts aloud in order to document and analyze them afterwards.

During the interview before the story was played through, Proband 1 (age between 40 and 60) emphasized that she did not want to use any drugs or technologies to live longer. She justified this by saying that she would rather have a good life than a long one in this world. Nevertheless, in the last question she chose to use life-sustaining drugs. She also made a different choice than expected when deciding on the form of the retirement home with human or machine care. She said in the previous questioning that she would rather entrust her life to a human rather than a machine, but then opted for mechanical care by robots.

At the decision points in the interactive narrative, Proband 2 (age between 40 and 60) behaved as expected from his answers to the previous survey. In each case, he decided on the technical support offered. Nevertheless, he finally decided on a retirement home with human care. The openness to new technologies is 
evident over long stretches along the narrative. But finally a limit to openness regarding the use of technology has also become apparent.

Proband 3 (age between 60 and 80) had already shown a rather defensive attitude towards new technologies in the previous survey. This attitude has also been reflected throughout the story. He has always sought human contact. He also showed a certain fear of technologies. Nevertheless, positive aspects of smart gadgets were also recognized in the course of the story. At the beginning a positive attitude towards living in a retirement home was shown. However, when he had to make the decision, he chose the option of living in a shared apartment for elderly people.

At the decision points in the interactive narrative, Proband 4 (age between 20 and 40) behaved as expected from his answers to the previous survey. The decision to use technology to maintain autonomy was always secondary to human care.

Proband 5 (age between 20 and 40) showed an analogous behavior to proband 4 . The interesting difference occurred at the end. He chose a home for the elderly with robotic care, which could not be deduced from the previous behavior.

Proband 6 (age between 60 and 80) had already clearly expressed his support for the use of technical aids in the previous survey. This attitude was evident throughout all decision points of the interactive narrative.

\section{CONCLUSIONS}

The findings of this mini survey show that an interactive story, presented online as a Twine, certainly stimulated thinking in the probands. The technologies chosen in the interactive story triggered a discourse among the test subjects. Thanks to the qualitative approach, these thought processes could be analyzed and evaluated. With only six test persons, statements are not resilient. An expansion of the number of test persons is planned in a next step.

Through the development of a PESTLE analysis and the future scenarios based on it, a real environment could be created for the test persons. It has to be taken into account that especially in the second and third stage a view into the future was ventured, which posed challenges to the test persons in different aspects. During the preparation time, an intensive examination of the senior citizens' care was carried out, both the care taking place today and that to be expected in the future. The expected technological development was researched in order to develop a feeling for which innovations can and must be expected in the coming years. For the test persons, who did not accompany this preliminary work and were only provided with explanations within the interactive story, some statements seemed rather futuristic and surprising.

The division of the story into three stages has proven to be a successful approach to take the test persons on a mental journey into the future and to provide them with appropriate information on the way there. There were some concerns in the development of the story with regard to the amount of information conveyed in some passages. Nevertheless, the impression was created that it was possible to slowly introduce the test persons to the story and to allow them to gradually familiarize themselves with the development, the scenarios and the questions. It was found for all test persons that the explanations and questions triggered a reaction throughout the story. The probands have, perhaps for the first time, dealt with this topic, have thought about it in different ways throughout the narrativ, and have thus gained a more differentiated view of the use of technology. How intensively this topic can occupy people was evident for all the probands. All of them have also developed an ever greater need for exchange and discussion as the story has progressed.

Autonomy, competence and social integration is most probably of great importance for all people. With this kind of interactive story, it was possible to get the test persons to gradually come to terms with such thoughts. Only then did the dilemmas become transparent to the test persons and only then could they deal with them. With increasing understanding, the test persons were also in the condition to experience and feel the dilemmas. When this point was reached, this feeling and understanding was also influencing the decisions. The statement to want to have a good rather than an especially long life can be mentioned at this point. Putting oneself into the future today can partly be achieved with an interactive story. 


\section{REFERENCES}

Behles, S. (2009). Interactive Storytelling: Multilineare Stories - Eine Einführung in die Thematik. GRIN Verlag.

Behrens, J., \& Zimmermann, M. (2006). Das Bedürfnis nach Selbstbestimmung bei Pflegebedürftigkeit. Zeitschrift für Gerontologie und Geriatrie, 39(3), 165-172. https://doi.org/10.1007/s00391-006-0389-z

Bendel, O. (Ed.). (2018). Pflegeroboter. Gabler Verlag. https://doi.org/10.1007/978-3-658-22698-5

Biasiucci, A., Franceschiello, B., \& Murray, M. M. (2019). Electroencephalography. Current Biology, 29(3), R80-R85. https://doi.org/10.1016/j.cub.2018.11.052

Bleses, H. M. (2019). Pflege 4.0: Zur Komplexität der Digitalisierung. Pflege, 32(6), $291-293$. https://doi.org/10.1024/1012-5302/a000697

Brucker-Kley, E., \& Keller, T. (2020a). Beyond Digitalization: "My Boss Is Artificial.” In F. Matos, V. Vairinhos, I. Salavisa, L. Edvinsson, \& M. Massaro (Eds.), Knowledge, People, and Digital Transformation: Approaches for a Sustainable Future (pp. 37-54). Springer International Publishing. https://doi.org/10.1007/978-3-030-40390-4_4

Brucker-Kley, E., \& Keller, T. (2020b). Digital Futures: Szenarien am Rande der Technologischen Singularität. ZHAW Zürcher Hochschule für Angewandte Wissenschaften. https://doi.org/10.21256/zhaw-19471

Brucker-Kley, E., \& Keller, T. (2019). Exploring the Potential of Immersive Narrative Scenarios to Identify Design Criteria for our Digital Future(s). 2019 8th International Congress on Advanced Applied Informatics (IIAI-AAI), 499-504. https://doi.org/10.1109/IIAI-AAI.2019.00108

Brucker-Kley Elke. (2020, September 23). Die Zukunft der Seniorenbetreuung. Digital Futures. https://digitalfutures.ch/die-zukunft-der-seniorenbetreuung/

Calvaresi, D., Cesarini, D., Sernani, P., Marinoni, M., Dragoni, A. F., \& Sturm, A. (2016). Exploring the ambient assisted living domain: A systematic review. Journal of Ambient Intelligence and Humanized Computing, 2(8), $239-257$. https://doi.org/10.1007/s12652-016-0374-3

Deci, E. L., \& Ryan, R. M. (2010). Self-Determination. In The Corsini Encyclopedia of Psychology (pp. 1-2). American Cancer Society. https://doi.org/10.1002/9780470479216.corpsy0834

Demenz und Technologie - Eine Trendübersicht (gedruckt): Alzheimer Schweiz. (n.d.). Retrieved October 8, 2020, from https://www.alzheimer-schweiz.ch/de/publikationen-produkte/produkt/demenz-und-technologie-einetrenduebersicht-gedruckt/

Es wird ernst mit dem demografischen Wandel! | Avenir Suisse. (n.d.). Retrieved October 8, 2020, from https://www.avenirsuisse.ch/demografie_es-wird-ernst-mit-dem-demografischen-wandel/

Hevner, A. R., March, S. T., Park, J., \& Ram, S. (2004). Design Science in Information Systems Research. MIS Quarterly, 28(1), 75-105.

Johnson, B. D. (2011). Science Fiction Prototyping: Designing the Future with Science Fiction. Synthesis Lectures on Computer Science, 3(1), 1-190. https://doi.org/10.2200/S00336ED1V01Y201102CSL003

Khairul, M., Kamarudin, M. khairul amri, Wahab, N., Mohamad, M., Mohd Saudi, A. S., Samsurijan, M., Hafiz, M., Saad, M., Yusri, S., Aula, N., Sazali, A.-M., Fadhlina, N., Latif, A., Norsyafawati, S., Rahim, A., Najiha, N., \& Samsur-Ing, S. (2018). Population Growth and Economic Development in Developing and Developed Countries. International Journal of Engineering and Technology, 123-127.

Koenitz, H., Ferri, G., Haahr, M., Sezen, D., \& Sezen, T. İ. (2015). Interactive digital narrative: History, theory and practice. Routledge.

Kubek, V. (2020). Digitalisierung in der Pflege: Überblick über aktuelle Ansätze. In V. Kubek, S. Velten, F. Eierdanz, \& A. Blaudszun-Lahm (Eds.), Digitalisierung in der Pflege: Zur Unterstützung einer besseren Arbeitsorganisation (pp. 15-20). Springer. https://doi.org/10.1007/978-3-662-61372-6_3

Li, J., Esteban-Fernández de Ávila, B., Gao, W., Zhang, L., \& Wang, J. (2017). Micro/Nanorobots for Biomedicine: Delivery, Surgery, Sensing, and Detoxification. Science Robotics, 2(4). https://doi.org/10.1126/scirobotics.aam6431

Marikyan, D., Papagiannidis, S., \& Alamanos, E. (2019). A systematic review of the smart home literature: A user perspective. Technological Forecasting and Social Change, 138, 139-154. https://doi.org/10.1016/j.techfore.2018.08.015

Martini, M. L., Oermann, E. K., Opie, N. L., Panov, F., Oxley, T., \& Yaeger, K. (2020). Sensor Modalities for Brain-Computer Interface Technology: A Comprehensive Literature Review. Neurosurgery, 86(2), E108-E117. https://doi.org/10.1093/neuros/nyz286

Pirker, J., Gütl, C., Weghofer, P., \& Feichtner, V. (2014). Interactive Science Fiction Prototyping in Virtual Worlds: Fundamentals and Applications. International Journal of Recent Contributions from Engineering, Science \& IT (IJES), 2(3), 46-52.

Rieger, S. (2019). Die Enden des Körpers: Versuch einer negativen Prothetik. VS Verlag für Sozialwissenschaften. https://doi.org/10.1007/978-3-658-23032-6 
Ryan, R. M., \& Deci, E. L. (2000). Self-determination theory and the facilitation of intrinsic motivation, social development, and well-being. The American Psychologist, 55(1), 68-78. https://doi.org/10.1037//0003-066x.55.1.68

Salzburg Research. (n.d.). PESTLE-Technik | Methodenpool. Retrieved September 18, 2019, from https://methodenpool.salzburgresearch.at/methode/pestle-technik/

Someren, M. W. van, Barnard, Y. F., \& Sandberg, J. A. C. (1994). The think aloud method: A practical guide to modelling cognitive processes. Academic Press.

Twine / An open-source tool for telling interactive, nonlinear stories. (n.d.). Retrieved September 4, 2019, from https://twinery.org/

Wisser, K. (2018). Gebäudeautomation in Wohngebäuden (Smart Home): Eine Analyse der Akzeptanz. Springer Vieweg. https://doi.org/10.1007/978-3-658-23226-9

Zettl, A., \& Trübswetter, A. (2018). Digitale Transformation in der Pflege - Neue Ansätze für die nutzerzentrierte Implementierung. https://doi.org/10.18420/muc2018-up-0214 